\title{
GRAPHICAL DATA FLOW BASED IN TLS AND PHOTOGRAMMETRY FOR CONSOLIDATION STUDIES OF HISTORICAL SITES. THE CASE STUDY OF JUROMENHA FORTRESS IN PORTUGAL
}

\author{
L. Mateus $^{1}{ }^{*}$, J. Fernández ${ }^{1}$, V. Ferreira ${ }^{1}$, C. Oliveira ${ }^{1}$, J. Aguiar ${ }^{1}$, A. S. Gago ${ }^{2}$, P. Pacheco ${ }^{1}$, J. Pernão ${ }^{1}$ \\ ${ }^{1}$ CIAUD, Lisbon School of Architecture, University of Lisbon, Lisbon, Portugal (lmmateus, jorgefernandez, victor, 20130244, \\ jaguiar, apacheco,jnpernao)@ fa.ulisboa.pt \\ ${ }^{2}$ CERIS, IST, University of Lisbon, Av. Rovisco Pais 1, Lisbon, Portugal - antonio.gago @ tecnico.ulisboa.pt
}

\section{Commission II, WG II/8}

KEY WORDS: Graphical data flow, photogrammetry, terrestrial laser scanning, consolidation, rehabilitation

\begin{abstract}
:
This paper discusses the graphical data flow, based on terrestrial laser scanning (TLS) and photogrammetry, for the conservation and rehabilitation project of the Fortress of Juromenha, located nearby the Portuguese-Spanish border in the Alentejo Province.

First, we describe the strategy of data acquisition including GPS positioning, drone imagery, ground based imagery, and TLS survey. For the data input, this study considers two types of natures: quantitative and qualitative. Quantitative means anything that can be quantified such as a measurement, an orthoimage, a point cloud or a 3D model. Qualitative means more intangible information such as a perspective on the state of conservation of a surface, a texture, or an ambience. Second, we illustrate the processing step highlighting the challenges and defining the outcomes. Next, it is detailed what kind of data was extracted to prepare the basis for the documents to be used on the conservation project. This section is complemented with the analysis on how data was shared among the project team and how it was used. Finally, it is discussed how the nature of the data and information generated influenced the consolidation design.
\end{abstract}

\section{INTRODUCTION}

In the broad discipline of architecture, and particularly in conservation planning of historical sites, graphical documentation represents a cornerstone for a successful development. Since conservation agents still tend to rely mostly on 2D documentation, CAD drawings provide the base for conservation project. Planners of conservation projects are more familiar with planimetric documentation. Protocols and workflows are set over a 2D database. Even when advantage of $3 \mathrm{D}$ models in conservation has been recognized and conservation agents understand the value on three-dimensional data, usually these outputs are neither contracted nor requested. Many times, along the survey process, comprehensive as-built 3d models are developed (Hoon et al,, 2019; Remondino et al., 2010), but usually they are only used to extract 2D documentation, and there is not a real engagement with the 3D and its potential. Other reason that reinforces this disconnection, it is the fact that often, conservation studies begin only after the initial surveys are complete (Tucci et. al., 2011). This strengthens the division between service providers that conduct the survey in one side, conservation agents that use those surveys to develop their work on the other (Akristiniy, 2016). Summarizing, conservation agents don't use 3D because they aren't familiarized with it and they don't become familiar with 3D because they don't use it. This closes a vicious cycle that urges to break.

We defend that, although a professional border may exist, it is desirable that the initial step of the survey is included within the conservation planning. Conservation agents (architects, conservators, engineers, etc.) must take an active role in the surveying phase in order to get familiar with the (capacities and limitations of the) data and make a better use of it.
This is particularly relevant when techniques such as photogrammetry and TLS are employed. It is commonly considered the existence of a hyper-specialization on their usage, wiping them from the hands of conservationist agents. That is not currently true. The ample developed of remote sensing technologies during the last years, has brought a wide variety of user-friendly tools that enable non specialists to use TLS and photogrammetry data with satisfactory results (Remondino et al., 2011; Fernández-Hernandez et al., 2015). In this paper we first propose a data flow for the combination of multiple data source towards the creation of documents to be used in conservation planning. Second, we demonstrate that the $3 \mathrm{D}$ models were crucial not only to extract 2D documentation, but they were fundamental as source of qualitative and quantitative information about the site. In fact, they were used throughout the design phases, allowing virtual visits to the site to clarify dimensions, geometry, pathologies, ambiences, details, materials, preventing the team to go physically to the site more often.

\section{THE FORTRESS OF JUROMENHA}

The Fortress of Juromenha, located nearby the border between Portugal and Spain in the province of Alentejo, consists of two levels of fortification: i) an exterior perimeter, corresponding to the Sixteenth-century fortress, and ii) an interior fence, called the Medieval Wall. The Sixteenth-Century Fortress, of the outer walls, with an irregular plan, consists of four bastions and two exterior tenailles. The walls are surrounded by a moat bounded by the covered path which, in turn, is delimited by the counterscarp. The medieval fortress is constituted by sections of the castle where there are still visible the remains of nine

\footnotetext{
* Corresponding author
} 
rectangular towers, some of them in ruin and others that were rebuilt during the twentieth century by "Direcção Geral dos Edifícios e Monumentos Nacionais" - (DGEMN), the former governmental entity responsible for conducting public works in the Portuguese monuments during more than half of the twentieth century. One of these towers recently collapsed, in 2018 , and other parts of walls are showing strong degradation signs. Inside the walls there remains the church and the old jail, which were subject to conservation works during the twentieth century. Everything else, was either demolished or in ruin. The Fortress of Juromenha incorporates several phases of Portuguese military architecture, from the Islamic period, the beginning of Portuguese nationality and the modern period. The design of the modern fortress is due to the architect Nicolau de Langres. The construction was coordinated by the engineer Jean Gillot and António de Freitas. In figure 1 we can see a global view of the Juromenha Fortress. The current state of conservation has its roots in an explosion of the loaf in 1659 (Espanca, 1978; Amendoeira et al., 2005).

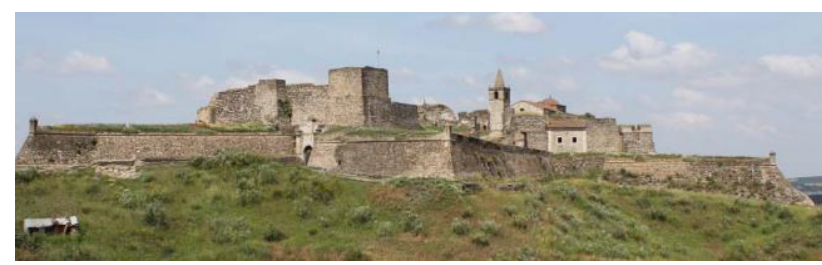

Figure 1. View of Juromenha Fortress site.

The degradation of recent years led the municipality of Alandroal to make efforts to promote the restoration of the fortress. To be able to apply for funding it was necessary to develop a consolidation and rehabilitation project. According to the Portuguese law, the intervention in listed architectural heritage needs to be supervised by the responsible entity for the management of cultural heritage (Direção Geral do Património Cultural - DGPC). For that purpose, the authors of this study were contracted to develop the consolidation and rehabilitation project. As it frequently happens, the budget and time was limited and therefore the strategy to develop the work had to take that into account.

\section{GRAPHICAL DATA FLOW}

An intervention in a big site such as Juromenha implies the involvement of many agents. In our case, there were surveyors (that were also architects), architects, archaeologists, conservation experts, and engineers, among which data must flow. Each expert receives information, qualitative and quantitative, that should be reliable, adds new layers of information to pass on to other experts. That should be a smooth process and the access to data should be as easy as possible. That can be a problem when dealing with big file sizes. Therefore, appropriate solutions should be considered and implemented. In figure 2 the data flow is synthesized.

\subsection{Data Acquisition}

To conduct a rehabilitation and a consolidation of the site it is required to articulate multiple types of data spanning from reliable geometric and radiometric data to historical and archive documentation. There is no solution allowing to gather all of this in a single process. Therefore, the acquisition strategy considered both field campaigns, on site, and documentary research in online databases and libraries.
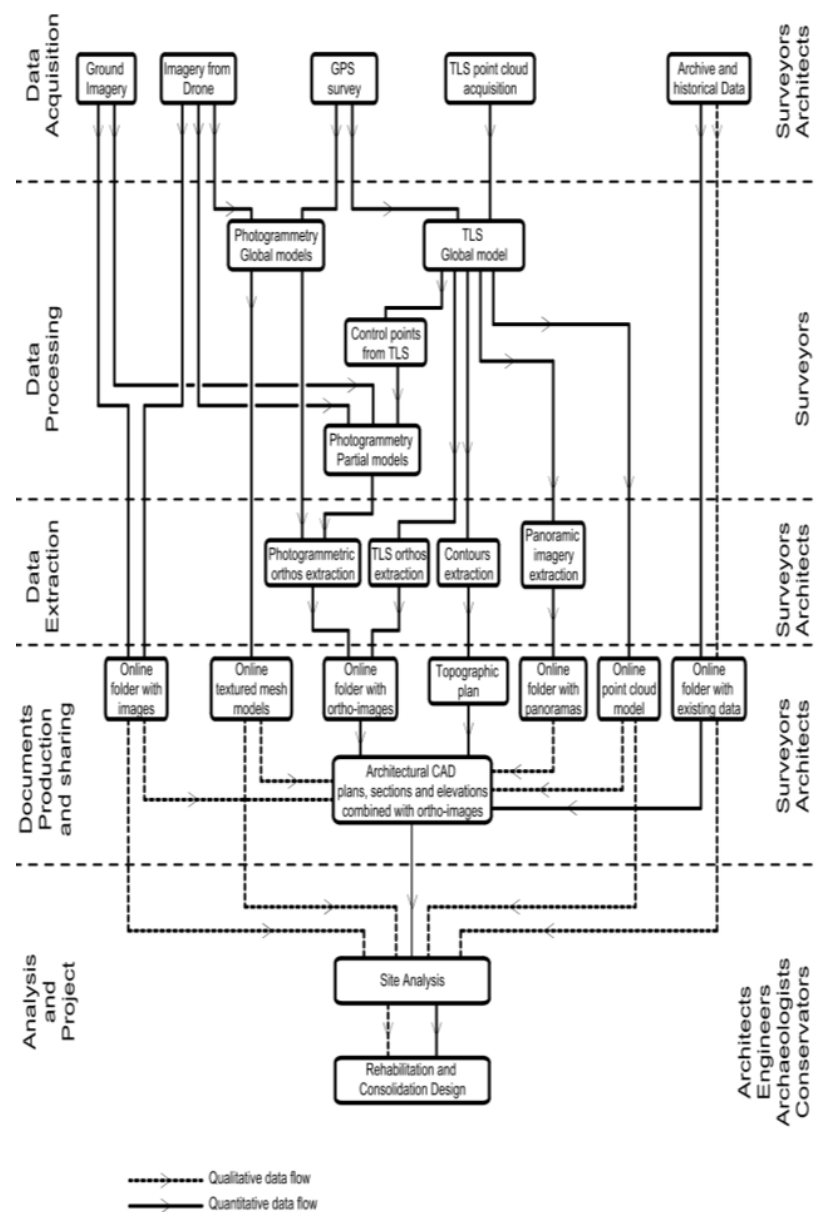

Figure 2. Graphical data flow: quantitative and qualitative.

Four main types of data were collected in the first phase of the project:

1. Terrestrial and aerial photos, providing a relevant set of data containing accurate texture information. The capture configuration followed the principle of Stereo Photogrammetry, where all relevant features where documented at least in a stereo pair. The aerial capture followed the principle of classic aerial photogrammetry: vertical photos with an overlapping of $80 \%$ in the longitudinal axis and $30 \%$ in the transverse axis. Approximately $10 \mathrm{k}$ photos were taken. For the aerial images it was used a DJI Phantom 4 drone.

2. TLS data providing and accurate geometrical information. A total of 370 scans at different resolutions were captured with the Faro Focus S120 laser scanner. It was considered a cloud to cloud registration strategy (Bellekens et al., 2015) and therefore there was big overlap between point clouds.

3. GPS control points heterogeneously distributed according to the characteristics of the site. The precision of the positioning was inferior to $2 \mathrm{~cm}$. It was used a Trimble R8 GNSS receiver. Surveyed points were used to globally orient the TLS point cloud model and the global photogrammetric model.

4. Historical and Archive data, obtained from different sources: SIPA (Sistema de Informação para o Património Arquitectónico) www.monumentos.pt; and historical research (Espanca, 1978; Maciel, 1985). 
Fieldwork data acquisition was conducted in one main campaign (7 days) and a secondary campaign (1 day). The later campaign was needed to cover missed areas.

\subsection{Data Processing}

\subsubsection{LASER SCANNING + GEOREFERENCING}

The registration of the scans followed a mixed registration strategy using Scene 7 software. First it was defined groups of scans corresponding to logical sections of the site. For these clusters it was followed a cloud to cloud registration method with global optimization. Then, the clusters were registered using natural features such as points and planes. This proved to be a more efficient strategy because the cloud to cloud method applied to the alignment of the clusters didn't return good results. We noticed that sometimes the cloud to cloud alignment process applied to clusters tended to local optima generating big discrepancies in some other parts. When all the clusters were registered, a global external orientation was performed using the GPS control points. This operation was done with a global precision of approximately $1.5 \mathrm{~cm}$.

A global top view of the TLS point cloud model can be seen in figure 3 .

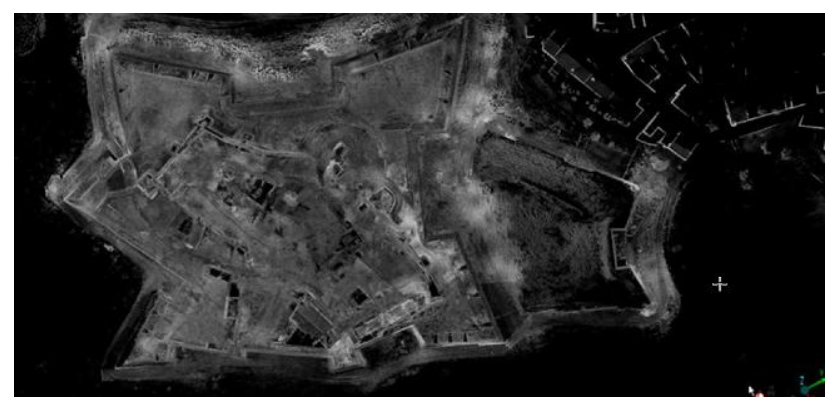

Figure 3. TLS point cloud model.

\subsubsection{PHOTOGRAMMETRY + GEOREFERENCING}

Texture enhanced/optimized models were created through photogrammetric approach (Mateus et. al., 2019). It was used the software Agisoft Photoscan version Pro. It was produced several partial models (fig. 4), with high resolution, and one global model with low resolution (fig. 5). The high-res models were intended to conduct detailed analysis on singular or complex elements. The low-res model was intended for online quick visualization purposes and global ortho generation. Similarly, to the TLS model, the low-res photogrammetric model was externally oriented based on the GPS control points.

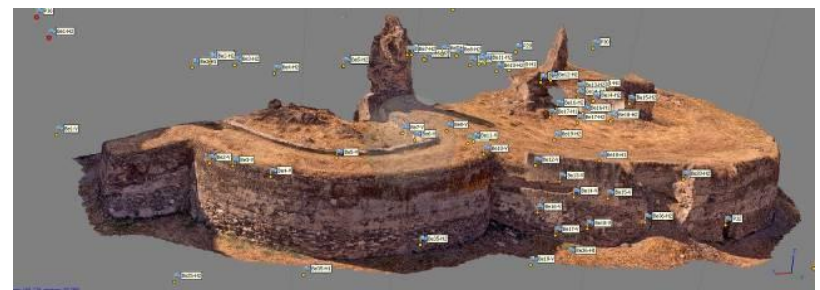

Figure 4. Partial model externally oriented with TLS control points.

For the partial models, due to the large amount of data and the aims to achieve a resolution of one point every $5 \mathrm{~mm}$, the site was divided in subgroups. Two main criteria were considered to conduct this subdivision: i) Number of image per project (no larger than 2.000 photos), and ii) limits of subgroups coinciding with limits of predefined 'Units of Study'.

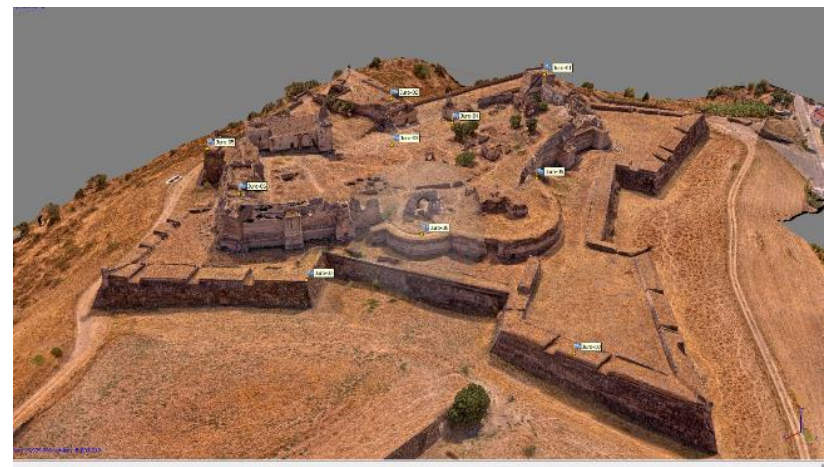

Figure 5. Global model with externally oriented with GPS points.

Based on this subdivision, five partial models were created: Full model (FM); outside face of outer wall (OO); outside face of inner wall (IO); inside face of outer wall (IO); and inside face of inner wall (II). These models were externally oriented using control points extracted from the laser scanning point cloud model. These corresponded to singular natural features that could be easily identified both in TLS data and in the images. This way it was achieved an accurate correspondence between TLS model and the photogrammetric models.

\subsection{Data Extraction}

Having in mind that data extraction should feed the production of documentation needed for the consolidation and rehabilitation studies, it was important to actively involve the architects in the process.

Four mains outputs were extracted:

1. True-Orthoimages from TLS to accurately represent geometrical properties of elements;

2. True-Orthoimages from Photogrammetry to accurately represent the materiality of elements (fig. 6 and fig. 7);

3. Contours;

4. Panoramic images corresponding to TLS stations.

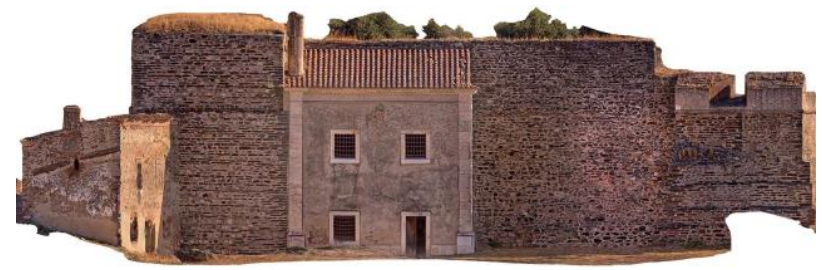

Figure 6. Sample of True-Orthoimage based in aerial photogrammetry high-res model.

First, a team of three architects was instructed on how to edit and extract data from TLS point clouds to further insert it in CAD. Within this process, it should also be generated control data to synchronously generate ortho-images from photogrammetric models and TLS model, i.e. to generate images exactly from the same point of view.

The architects team extracted all the contours needed to generate a topographic plan of the site. Then the orthos production was extensively planned, extracted and inserted in CAD. In those cases where we had curved surfaces, they were unrolled before othos generation (fig. 8).

Considering that the panoramas corresponding to the TLS stations provide a useful source of information about materials and their conservation state, these were also extracted. 


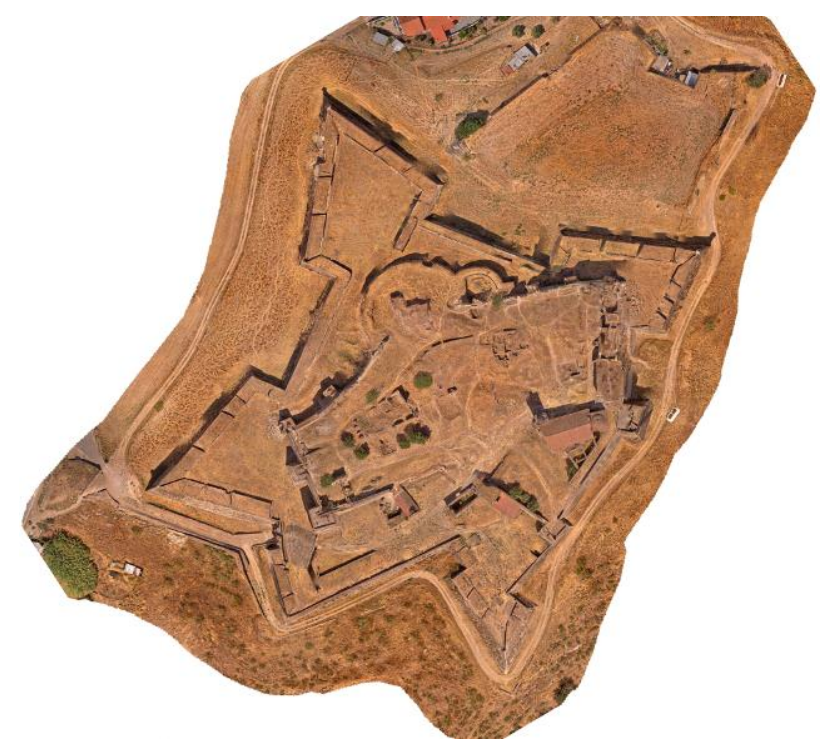

Figure 7. True-Orthoimage based in aerial photogrammetry low-res model.

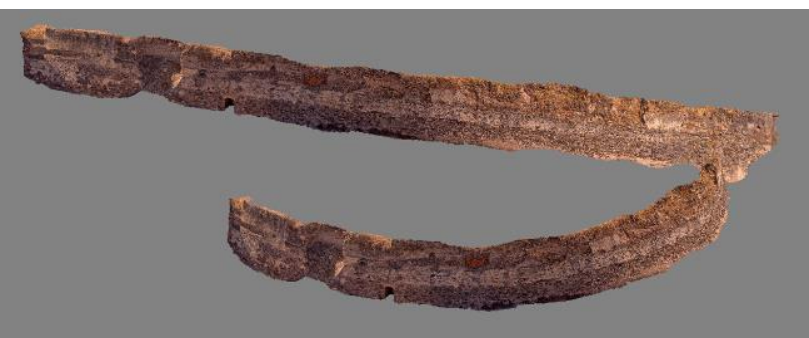

Figure 8. Curved surface (bottom) and unrolled surface (top).

\subsection{Documentation Production and sharing}

From the above-mentioned models and related extracted elements, it was generated and shared a set of documents to be used by all the elements of the team, including the architects, the engineers, the archaeologists and the conservators. The documents produced were:

1. Online Texture Low-Mesh available on Sketchfab platform. Sketchfab is a platform for 3D data storing and sharing (Statham, 2019), with a WebGL based viewer, allowing to interact with model from desktop and mobile devices. The low-mesh model was decimated to $500 \mathrm{k}$ triangles and an associated texture file of $8192 \times 8192$ pixels, fitting on Sketchfab requirement for geometric and texture limits (fig. 9). For this specific demonstration, to test the capacity of the created data to be reused in communication and citizen engagement strategies, the data was implemented in a video game environment. Textured Low-Mesh model was first adapted (in terms of topology and UV) to a suitable (FBX) format and data structure to suit a Video game Engine. A standard third person character and basic characteristics of collisions, scene limits and illumination were implemented. Draft results are illustrated in figure 10 .

2. Online repository with all the original images, with all the ortho images generated from the 3D models, and with the archive data. This was online accessible to all actors of the conservation project. Selected actors had rights not only on viewing and download but on data edition.

3. Online repository with the interactive panoramas generated from the TLS survey (fig. 11). These were generated using the Pannellum viewer (https://pannellum.org/).
4. Online TLS point cloud model and photogrammetric point cloud model. This was done using Potree (http://www.potree.org/). These models were mainly used to clarify measurements online. The advantage was that all the actors could access the models without the need to have it stored locally in multiple places (fig. 12).

5. Topographic plan based of contour lines, exposing shapes of buildings and walls together with information related to the elevation model. This element is an essential document to interpret relations across the entire site such as slopes, relation of constructions, and others (fig. 13).

6. Sections and elevations integrated with the topographic plan and with the ortho-images. All the previous documents contributed to the production of these documents either because they were quantitative inputs of because they were qualitative inputs crucial to clarify details about the features that were being represented.

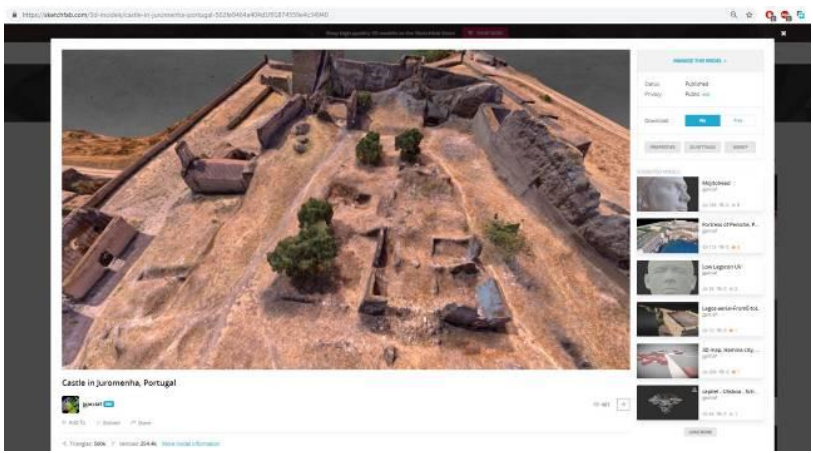

Figure 9. Global low-res photogrammetric model in the Sketchfab platform.

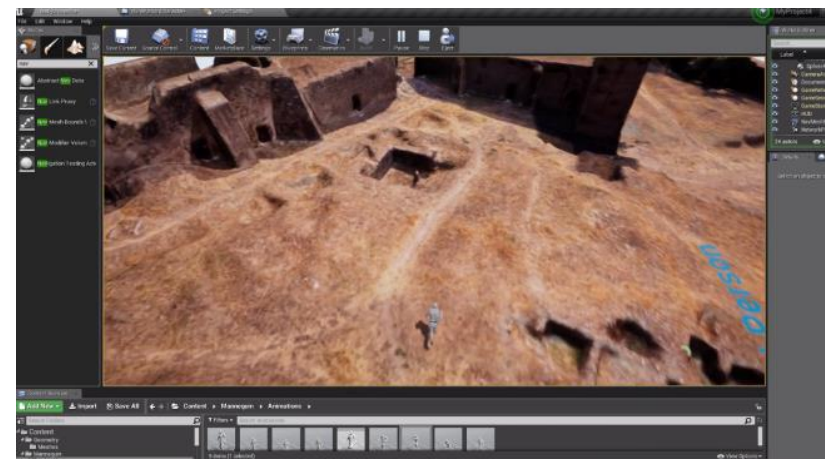

Figure 10. Digital 3D model integrated in Unreal Engine.

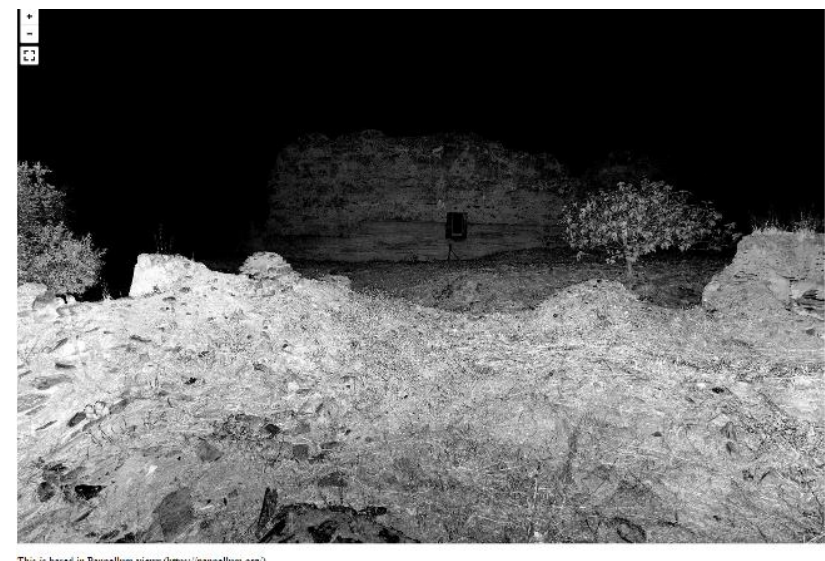

Figure 11. Interactive Panoramas based on TLS imagery. 


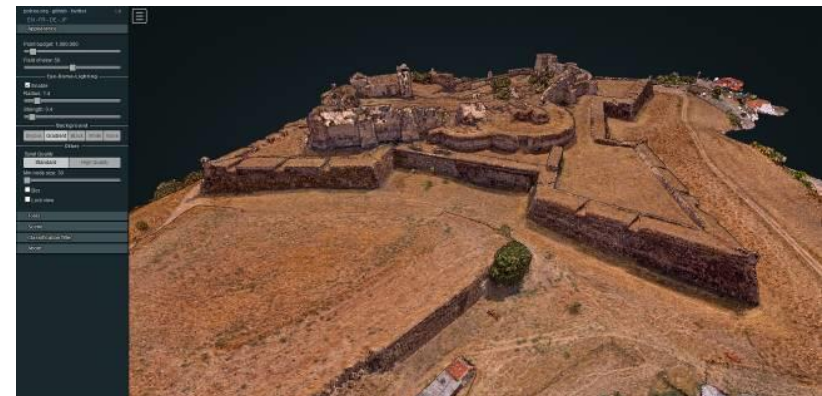

Figure 12. Online point cloud using Potree platform.

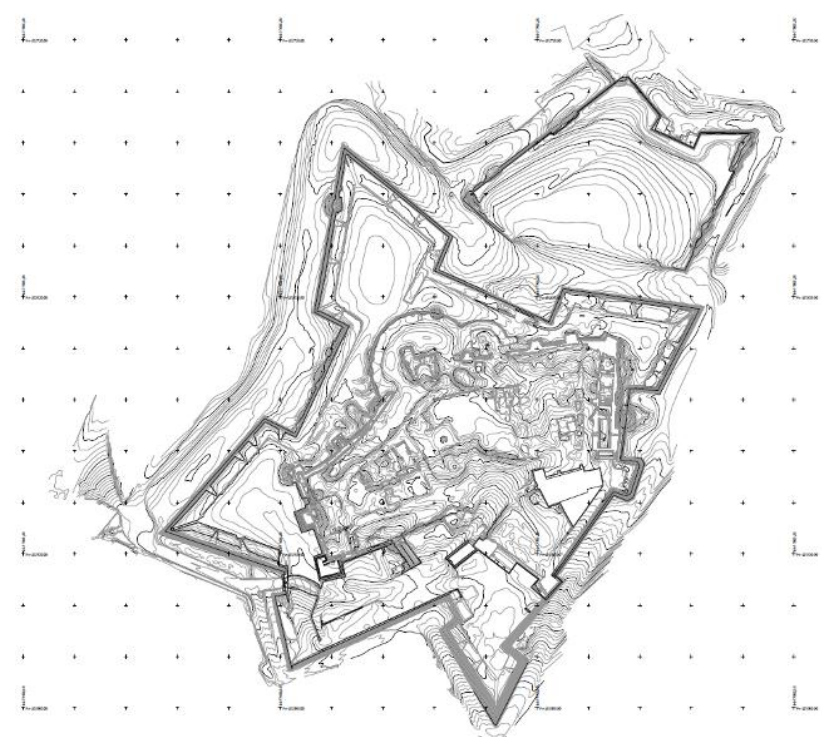

Figure 13. Topographic plan.

\subsection{Analysis and consolidation project}

Although the data flow presented in figure 2 show segmented steps, from data acquisition to analysis and consolidation, it doesn't mean that the overall process is linear. For example, as soon as the first images and models are available it is possible to start developing the archaeological analysis and it is possible for the architects to start sketching their design intentions. As the analysis process is developed, on demand data can be generated. For example, the ortho images extraction was done iteratively as more information was required.

Although the final documents produced to be delivered to the authorities were $2 \mathrm{D}$, the $3 \mathrm{D}$ played a key role in all the process. It allowed to accurately clarify many questions during the design, such as dimensions, deformations, metrics, pathologies, ambiences, details, materials, preventing the team to go more often to the site. The richness of the ortho images permitted a clear identification of the materials and pathologies. The 3D models clearly represented the deformations of walls. The textured models gave important information about materials and degradation forms. Somehow, we consider that the integration of this type of graphic data, 2D and $3 \mathrm{D}$, in context of Rehabilitation and Consolidation Project leads to higher quality results where a higher degree of certainty and confidence can be achieved.

Since the first visit to the site, the priority areas that required physical intervention have been identified: (i) the walls and towers of the Islamic and Medieval Wall; ii) the walls of the Sixteenth-Century Fortress.

Through the ortho-images generated by the photogrammetry partial models, it was possible to measure the original metrics of the earth structure retrieving important information about the constructive technique. With this specific information, it was proposed the consolidation of the Islamic and medieval walls with approximately 85 to $90 \mathrm{~cm}$ in each level of construction (fig. 14 and fig. 15). Based in the old walls remains, the design of the new walls allows the stability of the construction that can be assured by using constructive techniques compatible with the original ones. While working with a site that has been modified several times, knowing the period of each construction is crucial to a careful intervention. The analysis of colour and stereotomy allowed identifying all the materials used and determining the phases of construction.

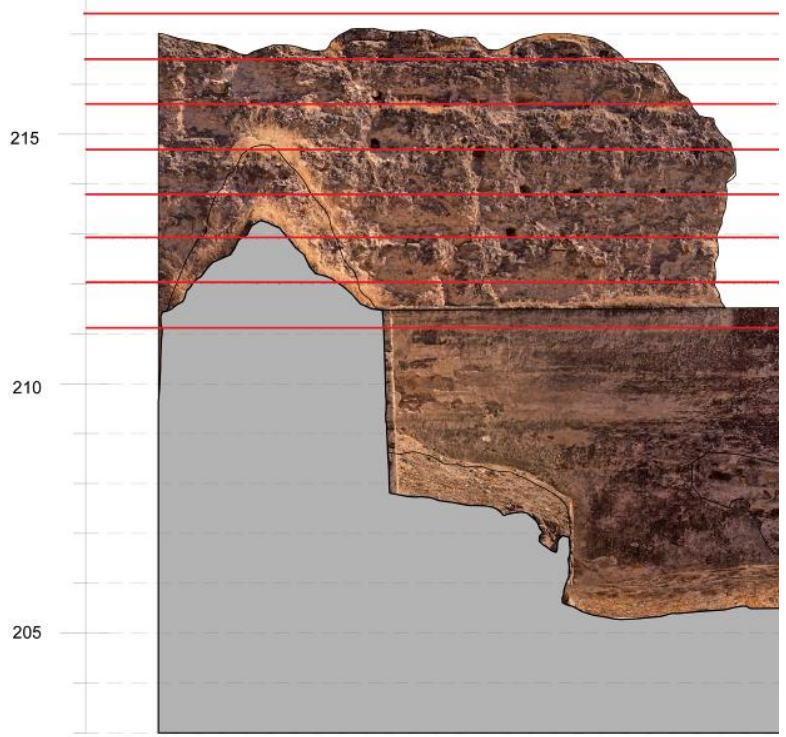

Figure 14. Image showing the metrics of the original earth

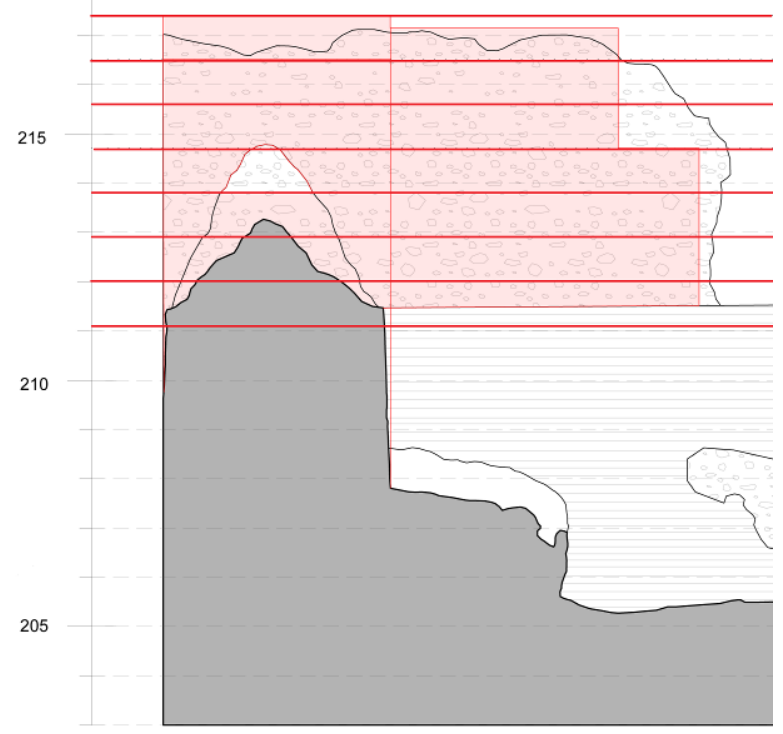

Figure 15. New intervention design.

Other elements that helped the design process of wall consolidation were the TLS ortho-images. The advanced state of degradation of the Islamic and medieval walls required several cross sections to determine the amount of material needed to restore the original thickness (fig. 16).

In addition, there were also other specific intervention places: i) the old north door; ii) the old south door; iii) the access to the 
tower; (iv) the two spaces adjacent to the entrance tunnel; v) parts of the outer fence of the fortification and new accessibilities to the village and to the river. These interventions seek to better establish connections to the different areas of the monument.

With help of photogrammetric ortho-image of the site plan, it was identified that the various walking routes that were made and are used by the people have safety problems. Based on these old paths, a new design was proposed to make it safer and more enjoyable.

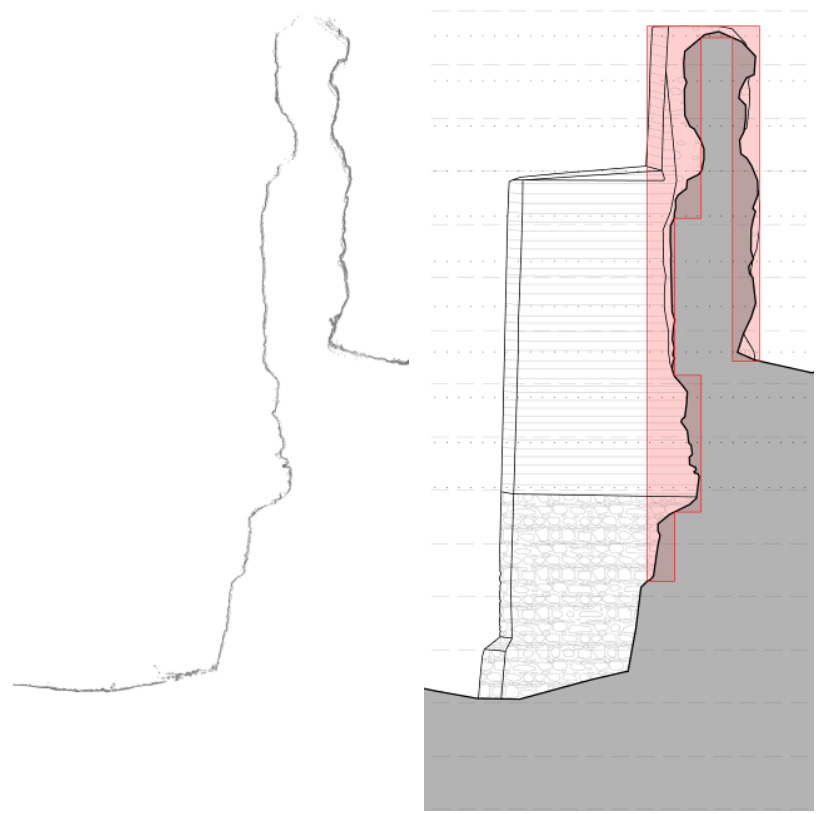

Figure 16. Left: Image showing the geometry of the original earth structure. Right: New intervention design.

Like the wall's consolidation, the following interventions also needed cross and longitudinal sections. The TLS global model allowed understanding the level differences that make it impossible to walk through the site. Some stairs and gangways were proposed to level the floor, after gathering all the measurements from vectorial drawings and from the 3D models. Besides that, the topographic plan, based in the contour lines of the TLS model, helped to identify the areas where a fundamental archaeology work needs to take place, so it is possible to make an intervention in the different zones mentioned above.

\section{CONCLUSIONS}

Currently Architects and Conservators rely mainly on 2D data to conduct conservation and rehabilitation projects of cultural heritage sites. Remote sensing technology for accurate 3D documentation and geomatic solutions for data representation remain under-used. To demonstrate and exploit the potentials of $3 \mathrm{D}$ data, in a feasible way, we need to set a comprehensive flow, considering: i) the specific requirements and needs of preservation projects, ii) the integration of technical equipment, and iii) the know-how of the team members.

In this study we developed a workflow ranging from data capture to site analysis and rehabilitation design strategy. To demonstrate it, we applied it in the rehabilitation and consolidation project of the Fortress of Juromenha, Portugal. Through a combination of technologies and methods (Terrestrial Laser Scanning; Digital Photogrammetry and GPS) we set up a data production package able to maximize the geometrical accuracy and faithfully represent the radiometric information of the site. This implementation is coordinated with a data production package where 3D information was properly converted to legible output looking to plan, design and conduct the rehabilitation strategy.

Although the outputs for the authorities were required in 2D format, the engagement between team members and nontraditional 3D broadened the scope of analysis and results in the restoration project. For example, 3D models were a source of inquiry during the preparation of vectorial drawings; online panoramas alongside with ortho images allowed to clarify details about materials and pathologies; the photogrammetric model was used to identify all the problems with materiality and discover old constructions techniques; the TLS model was used to give the precise information about measurements needed to develop the design project.

The main limitation of our development relates to the representativity of our case of study. Our demonstration site is significantly rich in terms of materials, extension and complexity. However, It also includes reasonable favourable conditions in terms of (i) spatial context (no neighbouring buildings, mobile elements or profuse vegetation); (ii) environmental conditions (no hard winds, snow, ), and (iii) singular materials (such as glass, water or shiny-metal structure or other radiometrically poor surfaces). Although this issue does not affect the interpretation or quality of data, it is required the application of our development in case studies with different conditions to refine and validate its usability.

The implementation of developed 3D models in Video game engines to promote the communication and citizen engagement strategies was experimented. We strongly believe that these outputs play a key role on $\mathrm{CH}$ communication, and directly support the conservation project by divulgating the intervention proposals and engaging the wider public. Given our results, follow-up studies are to be considered.

We consider that it is desirable to deeply integrate 3D outputs in the architectural design process. For that it is necessary to promote and develop formation strategies among architects and conservators to enable them to gain fluency in the use of $3 \mathrm{D}$ data.

\section{ACKNOWLEDGEMENTS}

The research leading to these results has been partially funded from the Research and Innovation Framework Programme (Marie Curie Actions) of the European Union's Horizon 2020 Framework Programme H2020-MSCA-IF-2016, project 3DSMoHC no. 747046

The authors also want to thank to the Municipality of Alandroal and to DGPC for the support given during the work.

\section{REFERENCES}

Akristiniy, V., 2016. Scientific aspects of the survey and evaluation of the technical state in implementation of preservation projects of cultural heritage objects. In: Conference proceedings of International Science Conference SPbWOSCE2016 on SMART City, Vol. 106, 2017, https://doi.org/10.1051/matecconf/201710601033

Amendoeira, P., Oliveira., L., 2005. Fortaleza de Juromenha. In: SIPA (Sistema de Informação do Património Arquitectónico), last access in may 2019, http://www.monumentos.gov.pt/Site/APP_PagesUser/SIPA.asp $\mathrm{x} ? \mathrm{id}=4461$ 
Bellekens, B., Spruyt, V., Berkvens, R., Penne, R. and Weyn, M., 2015. A Benchmark Survey of Rigid 3D Point Cloud Registration Algorithms. International Journal on Advances in Intelligent Systems, 8 (1 \& 2), pp. 118-127.

Espanca, T., 1978. Inventário Artístico de Portugal - vol. IX (Distrito de Évora, I). Lisboa, Academia Nacional de Belas Artes.

Fernández-Hernandez, J., González-Aguilera, D., RodríguezGonzálvez, P., and Mancera-Taboada, J., 2015. Image-based modelling from unmanned aerial vehicle (UAV) photogrammetry: An effective, low-cost tool for archaeological applications. Archaeometry, 57(1), pp. 128-145, https://doi.org/10.1111/arcm.12078

Hoon, Y.J., Hong, S., 2019. Three-dimensional digital documentation of cultural heritage site based on the convergence of terrestrial laser scanning and unmanned aerial vehicle photogrammetry. ISPRS International Journal of GeoInformation, 8(2), https://doi.org/10.3390/ijgi8020053

López, C., Peña, J.A., and Miralbés, R., 2019. 3D organic modeling using hybrid techniques with polygons. In: Lecture Notes in Mechanical Engineering, pp. 263-271, https://doi:10.1007/978-3-030-12346-8_26

Maciel, M. and Maciel, T., 1985. Novas Inscrições Romanas de Elvas e Juromenha. In: Separata do Ficheiro Epigráfico $n^{\circ} 15$, Coimbra

Mateus, L., Fernández, J., Ferreira, V., Oliveira, C., Aguiar, J., Gago, A. S., Pacheco, P., and Pernão, J., 2019. Terrestrial laser scanning and digital photogrammetry for heritage conservation: Case study of the historical walls of Lagos, Portugal. In: The International Archives of the Photogrammetry, Remote Sensing and Spatial Information Sciences, Vol. XLII-2/W11, pp. 843847, https://doi:10.5194/isprs-Archives-XLII-2-W11-843-2019

Remondino, F., Barazzetti, L., Nex, F., Scaioni, M., Sarazzi, D., 2011. UAV photogrammetry for mapping and $3 \mathrm{~d}$ modeling Status and future perspectives. In: The International Archives of the Photogrammetry, Remote Sensing and Spatial Information Sciences, Vol. XXXVIII-1/C22), pp. 25-31, https://doi.org/10.5194/isprsarchives-XXXVIII-1-C22-25-2011

Remondino F., Rizzi A., 2010. Reality-based 3D documentation of natural and cultural heritage sites - techniques, problems, and examples. Applied Geomatics, Vol. 2(3), pp. 85-100, https://doi.org/10.1007/s12518-010-0025-x

Statham, N., 2019. Scientific rigour of online platforms for 3D visualisation of heritage. Virtual Archaeology Review, Vol. 10(20), pp. 1-16, https://doi:10.4995/var.2019.9715

Tucci, G., Bonora, V., Nobile. A., and Bucalossi, L., 2011. Urban Heritage: the role of recording, documentation and information systems. Report in: Thematic section A "Tools and Methods for Historical Urban Landscape safeguard and development" of Euromed Heritage IV, "Mare Nostrum" project, Newsletter n. 5, July, pp. 22-25. 